\title{
Comparisons between female and male patients with mitral stenosis
}

\author{
C W Chiang, C T Kuo, W J Chen, C B Lee, T S Hsu
}

\begin{abstract}
Objective-To compare Doppler, echocardiographic, and clinical variables in female and male patients with mitral stenosis.

Design-Observational study in consecutive patients with mitral stenosis of cross sectional and Doppler echocardiographic and clinical variables and a retrospective search for a history of systemic embolism.

Setting-A medical centre with $\mathbf{3 0 0 0}$ beds, serving both urban and rural populations.

Patients-500 consecutive patients with an echocardiographic mitral valve area of $2 \mathrm{~cm}^{2}$ or less. $331(66 \cdot 2 \%)$ were female and $169(33.8 \%)$ male (mean (SD) ages of 49 (13) and 48 (14) respectively).

Main outcome measures-Mitral valve areas by echocardiographic planimetry and Doppler pressure half-time method, peak early diastolic mitral velocity and pressure gradient, echocardiographic score of mitral valve, left atrial end systolic diameter, frequency of left atrial thrombus and smoky echoes as well as various valve lesions detected with Doppler and echocardiography, cardiac rhythm, symptomatic functional class of heart failure, and history of systemic embolism.
\end{abstract}

Results-The prevalence of significant tricuspid $(22 \% v 9 \%, P<0.001)$ and pulmonary regurgitation $(5 \%$ v $1 \%, P=$ 0.018 ) was higher in the female patients than in the male patients. Female patients also had a higher peak regurgitant velocity $(3.2(0.7) v 2.9(0.7) \mathrm{m} / \mathrm{s}, \mathbf{P}=$ $0.007)$ and pressure gradient (41 (21) $v 36$ (19) $\mathrm{mm} \mathrm{Hg}, \mathbf{P}=0.010$ ) across the tricuspid valve. However, the male patients had a higher echocardiographic score (9.7 (2.4) v 7.0 (2.3), $\mathbf{P}<0.001)$ and $\mathbf{a}$ smaller Doppler-derived mitral valve area (0.9 (0.4) $\left.v 1.0(0.4) \mathrm{cm}^{2} P=0.027\right)$. There were no differences between the female and the male patients in mitral valve area measured by planimetry, peak early diastolic mitral velocity and pressure gradient, and left atrial end systolic diameter or in the prevalence of atrial fibrillation, left atrial thrombus, left atrial smoky echoes, significant aortic stenosis, aortic regurgitation, or heart failure of New York Heart Association class III or IV.
Conclusions-Female patients not only had a higher prevalence of mitral stenosis but also had a higher prevalence of associated tricuspid and pulmonary regurgitation along with a higher velocity and gradient of tricuspid regurgitation. The echocardiographic score was higher in male patients, however. These findings suggest that the pathophysiology of mitral stenosis is different in the two sexes and that gender should be taken into account when therapeutic strategies are formulated.

(Br Heart F 1994;72:567-570)

Keywords: mitral stenosis; gender; echocardiography.

Recently, attention has been focused on the relation between gender and cardiovascular diseases. ${ }^{1}$ The recognition of physiological or pathological differences in male and female patients may lead to more appropriate treatments.

Despite its decline in developed countries rheumatic heart disease remains the leading cause of death from heart disease in those aged 5-24 in most part of the world. ${ }^{2}$ Its incidence in Taiwan was 1.4 per 1000 children in 1970 and 0.6 per 1000 children in $1985 .^{3}$ Mitral stenosis is more common in females than in males. ${ }^{4}$

We compared various Doppler, echocardiographic, and clinical variables in female and male patients with mitral stenosis to see whether gender affected the pathophysiology of this condition.

\section{Patients and methods}

PATIENTS

Consecutive patients who were older than 15 and had a mitral valve area of $\leqslant 2.0 \mathrm{~cm}^{2}$ were enrolled in the study (331 female patients $(66 \cdot 2 \%)$ and 169 male $(33 \cdot 8 \%))$. We excluded patients who had had open heart surgery or percutaneous balloon dilatation of the mitral valve.

\section{CLINICAL VARIABLES}

The clinical variables examined included age, body surface area, cardiac rhythm, and presence or absence of significant heart failure (defined as New York Heart Association class III or IV) history of systemic embolism, and current use of anticoagulant and diuretics. 
DOPPLER AND ECHOCARDIOGRAPHIC VARIABLES Complete Doppler and echocardiographic examinations were performed with a Hewlett Packard Sonos 1000 ultrasound system using both $2.5 \mathrm{MHz}$ and $5 \mathrm{MHz}$ transducers from transthoracic windows. The examined variables included: mitral valve area; echocardiographic mitral valve score $^{5}$; peak early diastolic mitral velocity; left atrial end systolic diameter; presence or absence of significant (more than a mild degree of) aortic stenosis, aortic regurgitation, mitral regurgitation, and pulmonary regurgitation; peak systolic velocity of tricuspid regurgitation; and the presence or absence of left atrial thrombus or smoky echoes. The mitral valve area was determined by two dimensional planimetry and the Doppler pressure half-time method..$^{6-8}$ The left atrial end systolic diameter was measured on the $M$ mode echocardiogram recorded in the parasternal long axis view. Measurements were made according to the American Society of Echocardiography recommendations. ${ }^{9}$ Left atrial thrombus was detected by a $2.5 \mathrm{MHz}$ transducer from the transthoracic approach. ${ }^{10}$ We used a $5 \mathrm{MHz}$ transducer to detect atrial smoky echoes ${ }^{11-13}$ because it was more sensitive than a $2.5 \mathrm{MHz}$ transducer. ${ }^{13}$ We prefer the term "smoky echoes" to "spontaneous echo contrast" because some patients with severe tricuspid regurgitation or right heart failure have bright moving spots (caused by microbubbles) in the inferior vena cava or hepatic vein identical to those appearing in contrast echocardiography. We reserve the term "spontaneous echo contrast" for this echo pattern and use the term "smoky echoes" for the finer, lighter whorling echoes (which probably originate from aggregated red blood cells) ${ }^{13}$ that appeared in the left atrium in patients with severe mitral stenosis. Significant aortic stenosis was defined as an

Comparisons between female and male patients with mitral stenosis (mean (SD))

\begin{tabular}{lccc}
\hline Variable & $\begin{array}{l}\text { Females } \\
(n=331)\end{array}$ & $\begin{array}{l}\text { Males } \\
(n=169)\end{array}$ & $P$ value \\
\hline Age (yr) & $49(13)$ & $48(14)$ & $0 \cdot 674$ \\
Body surface area $\left(\mathrm{m}^{2}\right)$ & $1 \cdot 50(0 \cdot 11)$ & $1 \cdot 72(0 \cdot 11)$ & $<0 \cdot 001^{\star}$ \\
Mitral area by echo $\left(\mathrm{cm}^{2}\right)$ & $1 \cdot 0(0 \cdot 4)$ & $1 \cdot 0(0 \cdot 4)$ & $0 \cdot 670$ \\
Mitral area by Doppler $\left(\mathrm{cm}^{2}\right)$ & $1 \cdot 0(0 \cdot 4)$ & $0 \cdot 9(0 \cdot 4)$ & $0 \cdot 027^{\star}$ \\
MS score & $7 \cdot 0(2 \cdot 3)$ & $9 \cdot 7(2 \cdot 4)$ & $<0 \cdot 001^{\star}$ \\
V of MS (m/s) & $1 \cdot 9(0 \cdot 4)$ & $1 \cdot 9(0 \cdot 4)$ & $0 \cdot 910$ \\
PG of MS (mm Hg) & $15(6)$ & $15(6)$ & $0 \cdot 810$ \\
LADs (mm) & $50(11)$ & $51(12)$ & $0 \cdot 674$ \\
Prevalence of: & & & \\
AF & $248 / 331(75 \%)$ & $128 / 169(76 \%)$ & $0 \cdot 676$ \\
Embolism & $93 / 331(28 \%)$ & $51 / 169(30 \%)$ & $0 \cdot 727$ \\
CHF (NYHA class III or IV) & $139 / 331(42 \%)$ & $57 / 169(34 \%)$ & $0 \cdot 064$ \\
LA thrombus & $109 / 331(33 \%)$ & $47 / 169(28 \%)$ & $0 \cdot 335$ \\
LA smoky echoes & $63 / 331(19 \%)$ & $39 / 169(23 \%)$ & $0 \cdot 252$ \\
AS & $20 / 331(6 \%)$ & $15 / 169(9 \%)$ & $0 \cdot 188$ \\
AR & $53 / 331(16 \%)$ & $39 / 169(23 \%)$ & $0 \cdot 062$ \\
MR & $65 / 331(20 \%)$ & $28 / 169(17 \%)$ & $0 \cdot 404$ \\
TR & $73 / 331(22 \%)$ & $15 / 169(9 \%)$ & $<0 \cdot 001^{\star}$ \\
PR & $17 / 331(5 \%)$ & $2 / 169(1 \%)$ & $0 \cdot 018^{\star}$ \\
V of TR (m/s) & $3 \cdot 2(0 \cdot 7)$ & $2 \cdot 9(0 \cdot 7)$ & $0 \cdot 007^{\star}$ \\
PG of TR (mm Hg) & $41(21)(18 \%)$ & $36(19)$ & $0 \cdot 010^{\star}$ \\
Use of anticoagulant & $60 / 331(18 \%)$ & $41 / 169(24 \%)$ & $0 \cdot 168$ \\
Use of diuretics & $253 / 331(76 \%)$ & $113 / 169(67 \%)$ & $0 \cdot 162$ \\
\hline
\end{tabular}

$\mathrm{V}$ and PG of MS, peak early diastolic velocity and pressure gradient (calculated by Bernoulli quation: $P G=4 V^{2}$ ) of mitral stenosis; LADs, left atrial end systolic diameter; $A F$, atrial fibrillation; CHF (NYHA class III or IV), congestive heart failure (New York Heart Association class III or IV); AS, aortic stenosis; AR, aortic regurgitation; MR, mitral regurgitation; TR, tricuspid regurgitatioon; PR pulmonary regurgitation; V and PG of TR, peak systolic velocity and pressure gradient (calculated by Bernoulli equation) of tricuspid regurgitation.

$\star$ Statistically significant. aortic valve area of $\leqslant 1 \cdot 2 \mathrm{~cm}^{2}$ calculated by the continuity equation. ${ }^{14}$ Significant aortic regurgitation or pulmonary regurgitation was defined as a ratio of jet width to left or right ventricular outflow tract diameter of $\geqslant 25 \% . .^{15}$ Significant mitral regurgitation or tricuspid regurgitation was defined as a ratio of jet width to left or right atrial area of $\geqslant 20 \% .{ }^{15}$ The pressure gradient was calculated from the Bernoulli equation (pressure gradient $=$ $4 \times$ square of velocity).

\section{STATISTICAL ANALYSIS}

Values are expressed as mean values (1 SD) for continuous variables. Comparisons between the two groups were made by a twotailed Student's unpaired $t$ test for continuous variables and by a $\chi^{2}$ test for binary variables. Differences were regarded as significant when the $P$ value was $<0.05$.

\section{Results}

In our study there were twice as many female patients as male patients. In Taiwan the sex ratio of the general population over 15 years of age is $0.93: 1 .{ }^{16}$ The table shows comparisons of various Doppler, echocardiographic, and clinical variables in male and female patients. Tricuspid or pulmonary regurgitation were more common in the female patients $(22 \% v 9 \%, \mathrm{P}<0.001$ and $5 \% v 1 \%$, $P=0.018$, respectively). Female patients also had higher peak systolic velocity $(3.2(0.7) v$ $2.9(0.7) \mathrm{m} / \mathrm{s}, \mathrm{P}=0.007)$ and pressure gradient of the tricuspid regurgitation jet (41(21) $v$ $36(19) \mathrm{mm} \mathrm{Hg}, \mathrm{P}=0.010$ ). Heart failure of New York Heart Association class III or IV tended to be more common in the female patients $(42 \% v 34 \%, P=0.064)$. The male patients had a higher echocardiographic score $(9.7(2.4) v 7.0(2 \cdot 3), \mathrm{P}<0.001)$ and smaller Doppler-derived mitral valve area $(0.9(0.4) v$ $\left.1.0(0.4) \mathrm{cm}^{2}, P=0.027\right)$. Important aortic regurgitation tended to be more common in the male patients $(23 \% v 16 \%, P=0.062)$. None the less, the mitral valve area measured by planimetry was similar in female and male patients $\left(1 \cdot 0(0.4) v 1 \cdot 0(0.4) \mathrm{cm}^{2}\right)$. Nor were any of the other variables significantly different in the male and female patients.

\section{Discussion}

HIGHER PREVALENCE OF MITRAL STENOSIS IN FEMALE PATIENTS

The pathogenesis of rheumatic heart disease is not completely understood. Although it is an acquired disease caused by group A streptococcal infections, ${ }^{17-20}$ it rarely develops even after the most virulent streptococcal infections. Consequently, the issue of host predisposition is often raised. ${ }^{2122}$ The mechanisms leading to cardiac damage have not been clearly defined. What part does gender play? Our study confirmed the well known finding that rheumatic mitral stenosis is more common in female patients. ${ }^{4} \mathrm{~A}$ constitutional predisposition or sex linked inheritance may be involved. 
HIGHER ECHOCARDIOGRAPHIC SCORE AND SMALLER DOPPLER-DERIVED MITRAL VALVE AREA IN MALE PATIENTS

The higher echocardiographic score suggests a more severe mitral abnormality in male patients. The smaller Doppler-derived mitral valve area in the male patients accords with this suggestion. However, the mitral valve area derived from pressure half-time method may be inaccurate in various conditions. ${ }^{23-25}$ For example, chronic clinically significant aortic regurgitation may lead to underestimation of mitral valve area by the pressure half-time method. ${ }^{25}$ In our study, there was a trend (that did not achieve statistical significance) that more male patients had important aortic regurgitation (table). This might explain why the males had smaller Dopplerderived mitral area, whereas by planimetry the mitral valve areas were similar in the male and the female patients. Nevertheless, because the body surface area in the male patients $\left(1 \cdot 72(0 \cdot 11) v 1 \cdot 50(0 \cdot 11) \mathrm{m}^{2}, \mathrm{P}<0.001\right)$ was larger their mitral valve area may still be smaller in relation to body surface area. In any case the pathological changes of the mitral valve in the male patients are likely to be more severe, because of their higher levels of physical activity.

\section{HIGHER PREVALENCE OF ASSOCIATED}

TRICUSPID AND PULMONARY REGURGITATION AND HIGHER PULMONARY PRESSURE IN THE FEMALE PATIENTS

The higher prevalence of associated tricuspid and pulmonary regurgitation and the higher peak velocity and pressure gradient of tricuspid regurgitation jet suggest that pulmonary arterial pressure (by Bernoulli equation: pressure gradient $=4 \times$ square of velocity) was higher in the female patients. If the mitral valve lesion is less severe in the female patients, the higher pulmonary pressure suggests higher pulmonary resistance. There are three possible mechanisms leading to pulmonary hypertension in patients with mitral stenosis: (a) passive backward transmission of the raised left atrial and pulmonary venous pressures; (b) reactive arteriolar vasoconstriction, which presumably is triggered by the increase in pulmonary venous pressure (reactive pulmonary hypertension); and (c) organic obliterative changes in the pulmonary vasculature, which may be caused by a longstanding increase in pressure. In this study, the higher pulmonary pressure in the female patients is unlikely to be caused by backward transmission of left atrial pressure, because the mitral valve lesion may be more severe in the male patients than in the female patients. The higher pressure may be due to a higher reactivity and/or more organic obliterative changes of the pulmonary vasculature in the female patients.

\section{CLINICAL IMPLICATIONS}

This study showed pathophysiological differences between female and male patients with mitral stenosis. This means that it may be necessary to take gender into account in for- mulating therapeutic strategies for mitral stenosis. For example, interventions, such as percutaneous balloon dilatation of the mitral valve, may be needed at an earlier stage in female patients to prevent the development of severe pulmonary hypertension. In addition, the success rate may be higher in the female patients because their echocardiographic scores are lower. Further studies are required to confirm these speculations.

1 Wenger NK, Speroff L, Packard B. Cardiovascular health and diseases in women. $N$ Engl $f$ Med 1993;329: 247-56.

2 Argarwal BL. Rheumatic heart disease unabated in developing countries. Lancet 1981;ii:910-1.

3 Lue HC, Wu MH, Hwang BT, Meng CCL, Chao CC, Shen CT, Su WG, Yang CC, Chen SS, Hsieh JF, Chen CJ. Establishment of a rheumatic heart disease registry in Taipei: an early appraisal. NZ Med $\mathcal{F} 1988 ; 101: 410-1$.

4 Braunwald E. Valvular heart disease. In: Braunwald E(ed). Heart disease. Philadelphia: WB Saunders 1992;1007-77.

5 Wilkins GT, Weyman AE, Abscal VM, Block PC, Palacios IF. Percutaneous balloon dilatation of the mitral valve:
an analysis of echocardiographic variables related to outan analysis of echocardiographic variables related to out-
come and the mechanism of dilatation. Br Heart $\mathcal{F} 1988$; 60:299-308.

6 Hatle L, Angelsen B, Tromsdal A. Noninvasive assessment of atrioventricular pressure half-time by Doppler ultrasound. Circulation 1979;60:1096-104.

7 Smith MD, Handshoe R, Handshoe S, Kwan OL, DeMaria AN. Comparative accuracy of two-dimensional echocardiography and Doppler pressure half-time methods in assessing severity of mitral stenosis in patients with and without prior commissurotomy. Circulation 1986;73:100-7

8 Thomas JD, Weyman AE. Doppler mitral pressure halftime: A clinical tool in search of theoretical justification. f Am Coll Cardiol 1987;10:923-9.

9 Sahn DJ, De Maria A, Kisslo J, Weyman A. Recommendations regarding quantitation in M-mode echocardiography: result of a survey of echocardiographic measurements. Circulation 1978;58:1072-83.

10 Chiang CW, Pang SC, Lin FC, Fang BR, Kuo CT, Lee YS, Chang CH. Diagnostic accuracy of two-dimensional echocardiography for detection of left atrial thrombus in patients with mitral stenosis. F Ultrasound Med 1987,
6:525-9.

1 Iliceto S, Antonelli G, Sorino M, Biasco G, Rizzon P. Dynamic intracavitary left atrial echoes in mitral stenosis. Am $\mathcal{F}$ Cardiol 1985;55:603-6.

12 Chiang CW, Lin FC, Fang BR, Kuo CT, Lee YS, Chang $\mathrm{CH}$. "Sand-drift" echoes and thrombus formation in the left atrium. Am Heart $\mathcal{f} 1988 ; 115: 908-11$.

13 Sigel B, Coelho JO, Spigos DG, Flanigan DP, Schuller J, Kasprisin DO, et al. Ultrasonography of blood during stasis and coagulation. Invest Radiol 1981;16:71-6.

14 Richards KL, Cannon SR, Miller JF, Crawford MH Calculation of aortic valve area by Doppler echocardiography: a direct application of the continuity equation Circulation 1986;73:964-9.

15 Cooper JW, Nanda NC, Philpot EF, Fan P. Evaluation of valvular regurgitation by color Doppler. $f \mathrm{Am}$ Soc Echo 1989;2:56-66.

16 Health and Vital Statistics 2. Vital Statistics 1990; Department of Health, the Executive Yuan, Republic of China.

17 Taranta A. Rheumatic fever in children and adolescents, a long-term epidemiologic study of subsequent prophylaxis, streptococcal infections and clinical sequelae. IV Relation of the rheumatic fever recurrence rate per streptococcal infection to the titers of streptococcal antibodies. Ann Intern Med 1964;60(suppl 5):47.

18 Taranta A, Kleinberg E, Feinstein AR, Wood HF, Tursky E, Simpson R. Rheumatic fever in children and adolescents: a long-term epidemiologic study of subsequent prophylaxis, streptococcal infections and clinical sequelae. V. Relation of the rheumatic fever recurrence rate per streptococcal infection to pre-existing clinical per streptococcal infection to pre-existing clinical
features of the patients. Ann Intern Med 1964;60(suppl 5):58.

19 Johnson EE, Stollerman GH, Grossman BJ. Rheumatic recurrences in patients not receiving continuous prophylaxis. FAMA 1964;190:407-13.

20 Taranta A, Torosdag S, Metrakos J, Jegier W, Uchida I. Rheumatic fever in monozygotic and dizygotic twins. Proceedings of the tenth international congress of Rheumatology. Torino: Minerva Medica, 1961:96-98.

21 Taranta A. Rheumatic fever made difficult: a critical review of pathogenic theories. Pediatrician 1976;5:74.

22 Yoshimoya S, Pope $M$. Detection of immune complexes in acute rheumatic fever and their relationship to HLA-B5. f Clin Invest 1980;65:136-45.

23 Loyd D, Eng D, Ask P, Wranne B. Pressure half-time does not always predict mitr.

24 Thomas JD, Wilfins GT, Choong CYP, Abascal VM, Palacios IF, Block PC, Weyman AE. Inaccuracy of 
mitral pressure half-time immediately after percutaneous mitral valvotomy-Dependence on transmitral gradient and left atrial and ventricular compliance. Circulation 1988;78:980-93.
25 Chiang CW, Cherng WG, Chang FJ, Lin FC, Fan BR, Kuo CT, Lee YS. Effect of heart rate on pressure halftime in patients with mitral stenosis. Chang Keng I Hsueh 1992;15:72-7.

\section{Comment}

Chiang et al studied 500 consecutive patients with clinically important mitral stenosis to determine whether or not there are significant differences between the sexes in some of the echocardiographic variables commonly used in the clinical evaluation of patients with valvar heart disease. The data are of interest, if only because such an extensive characterisation of severe rheumatic mitral valve disease could no longer be undertaken in the western world-where the incidence of rheumatic heart disease has fallen and new cases are more likely to be detected at an earlier stage of the disease process.

Possible gender differences in the presentation and management of coronary artery disease have aroused considerable interest in recent years. Chiang et al suggest that gender differences extend to the manifestations of rheumatic mitral stenosis and that female patients had a higher prevalence and severity of tricuspid regurgitation although male patients (probably) had more severe mitral stenosis. They suggest that the pulmonary vascular response to mitral stenosis is greater in female patients, perhaps because the vascular reactivity of the pulmonary vascular bed is increased.

Whether these findings indicate a real gen- der difference or not is uncertain. The results suggest that mitral stenosis was more severe in males, but only just-mitral valve area estimated by Doppler echocardiography (pressure half-time method) was slightly less in males and the echocardiographic score was higher. This score, however, is a purely descriptive and subjective assessment. The mitral valve area measured by planimetry, the forward velocity across the valve, the pressure gradient, and left atrial diameter were the same in both sexes. The difference in peak tricuspid regurgitation velocity between the sexes $(0.3 \mathrm{~m} / \mathrm{s})$ is within the limits of the error of measurement of the technique. Consequently, the higher pressure gradient across the tricuspid valve in female patients (41 $v 36 \mathrm{~mm} \mathrm{Hg}$ ) may well have been overinterpreted. However, Chiang et al point out that if mitral valve area was corrected for body size, the gender difference in valve area would be even greater. There are examples where vasomotor tone of certain vascular beds is greater in female patients. Whether or not the data presented here are part of the same phenomenon is open to interpretation.

DIANA R HOLDRIGHT

Department of Cardiology, Middlesex Hospital, Mortimer Street, London W1N 8AA 